\title{
The Alpha-Melanocyte Stimulating Hormone Induces Conversion of Effector T Cells into Treg Cells
}

\author{
Andrew W. Taylor and Darren J. Lee \\ Department of Ophthalmology, Boston University School of Medicine, 72 East Concord Street, Boston, MA 02118, USA \\ Correspondence should be addressed to Andrew W. Taylor, awtaylor@bu.edu
}

Received 28 February 2011; Revised 20 June 2011; Accepted 4 July 2011

Academic Editor: Aruna V. Vanikar

Copyright ( $) 2011$ A. W. Taylor and D. J. Lee. This is an open access article distributed under the Creative Commons Attribution License, which permits unrestricted use, distribution, and reproduction in any medium, provided the original work is properly cited.

\begin{abstract}
The neuropeptide alpha-melanocyte stimulating hormone $(\alpha-\mathrm{MSH})$ has an important role in modulating immunity and homeostasis. The production of IFN- $\gamma$ by effector T cells is suppressed by $\alpha$-MSH, while TGF- $\beta$ production is promoted in the same cells. Such $\alpha$-MSH-treated T cells have immune regulatory activity and suppress hypersensitivity, autoimmune diseases, and graft rejection. Previous characterizations of the $\alpha$-MSH-induced Treg cells showed that the cells are CD4 ${ }^{+} \mathrm{T}$ cells expressing the same levels of CD25 as effector T cells. Therefore, we further analyzed the $\alpha$-MSH-induced Treg cells for expression of effector and regulatory T-cell markers. Also, we examined the potential for $\alpha$-MSH-induced Treg cells to be from the effector T-cell population. We found that the $\alpha-\mathrm{MSH}$-induced Treg cells are CD25 ${ }^{+} \mathrm{CD} 4^{+} \mathrm{T}$ cells that share similar surface markers as effector T cells, except that they express on their surface LAP. Also, the $\alpha$-MSH treatment augments FoxP3 message in the effector T cells, and $\alpha$-MSH induction of regulatory activity was limited to the effector $\mathrm{CD} 25^{+} \mathrm{T}$-cell population. Therefore, $\alpha$-MSH converts effector T cells into Treg cells, which suppress immunity targeting specific antigens and tissues.
\end{abstract}

\section{Introduction}

The melanocortin pathway is a highly conserved family of receptors and ligands that have important roles in regulating metabolism, pigmentation, and immunity [1-3]. The prototypic melanocortin, alpha-melanocyte stimulating factor $(\alpha-\mathrm{MSH})$, suppresses inflammation mediated by both innate and adaptive immunity. The neuropeptide $\alpha$-MSH inhibits NF-kB activation by blocking the intracellular signaling pathways initiated by TLR, scavenging, IL-1, and TNF $\alpha$ receptors in macrophages, dendritic cells, and neutrophils through the melanocortin 1 receptor $(\mathrm{MClr})$ and the melanocortin 3 receptor (MC3r) [4-11]. In addition, $\alpha$-MSH induces MClr expression, and transcription of proopiomelanocortin hormone in monocytes establishing a self-perpetuating immunosuppressive autocrine loop [12]. Because the serum levels of $\alpha$-MSH increase during the acute phase of inflammation [13] and the anti-inflammatory activity of $\alpha-\mathrm{MSH}$ has an antagonist relationship with proinflammatory mediators [2] suggests that $\alpha$-MSH has an important role in the resolution of inflammation and the maintenance of immune homeostasis.
The analysis of the molecular mechanisms of ocular immune privilege demonstrates the importance of $\alpha$-MSH in preventing and suppressing inflammation within the healthy eye $[14,15]$. Within the ocular microenvironment, the constitutively present $\alpha$-MSH has an important role in suppressing the activation of effector T-cells, and in the regional induction of Treg cells [14, 16-19]. Also, the melanocortin pathway has a role in resolving ocular autoimmune disease in converting a systemic effector $\mathrm{T}$ cell response into a regulatory $\mathrm{T}$-cell response specific to ocular autoantigens $[20,21]$. Injections of $\alpha$-MSH peptide or DNA plasmids encoding for $\alpha$-MSH have been used as experimental therapy to suppress graft rejection, inflammation, and autoimmune diseases in the eye and in the CNS [22-28]. Also, Treg cells induced by $\alpha$-MSH have been used in adoptive transfer experiments to suppress hypersensitivity, autoimmunity, and graft rejection $[17,29,30]$. These adoptive transfer experiments demonstrated that the activation of regulatory activity was antigen specific; however, the mechanisms of suppression were general and most likely mediated by TGF- $\beta$ produced by the Treg cells [17]. 
We have previously demonstrated that $\alpha$-MSH not only suppresses IFN- $\gamma$ production by activated effector $\mathrm{T}$ cells already programmed to be Th1 cells, but also made the $\mathrm{T}$ cells become functional CD $25^{+} \mathrm{CD} 4{ }^{+}$Treg cells that produce only TGF- $\beta[16,17,29]$. To see the effects of $\alpha-\mathrm{MSH}$ on the effector T cells; it is required for the effector $\mathrm{T}$ cells to be stimulated through their T-cell receptor (Tcr)-stimulation either by antigen presenting cells or by cross-linking using anti-CD3 antibody 2C11. The effects of $\alpha-\mathrm{MSH}$ is not through the Tcr, but through the melanocortin 5 receptor (MC5r) [17]. Blocking MC5r prevents $\alpha$-MSH induction of regulatory activity in the activated $\mathrm{T}$ cells. Further analysis of the $\alpha$-MSH-induced Treg cells show that the Treg cells after activation express message for IFN- $\gamma$ and TGF- $\beta$ at the same level as untreated activated Th1 cells [16]. Staining for intracellular IFN- $\gamma$ protein shows similar levels of the protein in $\alpha$-MSH-treated and -untreated effector T cells [31]. Treatment with $\alpha$-MSH enhances ubiquitination of intracellular IFN- $\gamma$ protein preventing the T cells from secreting IFN- $\gamma$ while allowing for free production and secretion of TGF- $\beta$. This demonstrated that $\alpha$-MSH manipulates effector $\mathrm{CD}^{+}$ $\mathrm{T}$ cells as they are Tcr-stimulated by altering the secretion of specific cytokines to make the $\mathrm{T}$ cells suppress or regulate immunogenic inflammation. This is not a transient effect, since it is possible to adoptively transfer these $\alpha$-MSHinduced Treg cells and effectively suppress hypersensitivity, autoimmune disease, and graft rejection in vivo $[17,29,30]$.

In this work, we assayed the $\alpha$-MSH-induced Treg cells and found that they are $\mathrm{CD} 25^{+} \mathrm{CD} 4^{+} \mathrm{T}$ cells, producing TGF- $\beta$ and expressing on their surface latency-associated peptide of TGF- $\beta$ (LAP). In addition, the results further support the potential for $\alpha$-MSH to convert effector T cells into functional Treg cells.

\section{Materials and Methods}

2.1. In Vitro Simulation and $\alpha-M S H$ Treatment of Effector $T$ Cells. C57BL/6 mice were purchased from Jackson Laboratories (Bar Harbor, ME). All mice were treated with the approval of the Schepens Eye Research Institute and the Boston University School of Medicine Institutional Animal Care and Use Committees. The immunization of the mice and isolation of lymph node $\mathrm{T}$ cells were as we have done before $[14,17,30,31]$. The mice were injected with $50 \mu \mathrm{L}$ of Complete Freund's Adjuvant fortified with $10 \mathrm{mg} / \mathrm{mL}$ desiccated Mycobacterium tuberculosis into the footpad. Seven days later; the draining popliteal lymph node was collected to obtain effector $\mathrm{T}$ cells. The lymph nodes were removed and placed in 5\% fetal bovine serum (FBS) in RPMI-1640 supplemented with $10 \mu \mathrm{g} / \mathrm{mL}$ Gentamycin (Sigma, St Louis, MO), $10 \mathrm{mM}$ HEPES, $1 \mathrm{mM}$ Sodium Pyruvate (BioWhittaker, Walkersville, MD), and $1 \mathrm{X}$ Nonessential Amino Acids (NEAA). The lymph nodes were made into a single cell suspension, depleted of red blood cells, and washed with serum free media (SFM), RPMI-1640 supplemented with $0.2 \%$ ITS+1-media supplement (Sigma), and $0.1 \%$ bovine serum albumin (BSA). The $\mathrm{CD}^{+} \mathrm{T}$ cells were isolated from the cell suspension using negative selection CD4 columns
( $R \& D$ Systems, Minneapolis, MN). The isolated CD4 ${ }^{+} \mathrm{T}$ cells (98\% $\mathrm{CD}^{+}$by flow cytometry analysis) were plated into the wells of 96-well plate at $1 \times 10^{6}$ cells per well. Into each well was added $1 \mu \mathrm{g}$ anti-CD3 (Tcr) 2C11 antibody (BD Biosciences, San Diego, CA), and $\alpha-\mathrm{MSH}$ (Bachem, Torrance, CA) at a physiological concentration of $30 \mathrm{pg} / \mathrm{mL}$ [14]. The cultures were incubated at $37^{\circ} \mathrm{C}, 5 \% \mathrm{CO}_{2}$ until collected for the assays described below.

2.2. Flow Cytometry Staining. Antibodies used for flow cytometry staining were anti-CD25-PerCP-Cy5.5 (BD Biosciences), anti-GITR-FITC (R\&D Systems), anti-CTLA4FITC (R\&D Systems), anti-CD127-PE (BD Biosciences), CD44-FITC (BD Biosciences), CD62L-FITC (BD Biosciences), anti-LAP-PerCP (R\&D Systems), anti-CD4-AF700 (Biolegend, San Diego, CA), and anti-CD25-APC-Cy7 (Biolegend). The cultured cells were collected at 72 hours or at 48 hours for LAP staining, and washed once in ice cold staining buffer (0.01 M PBS with 1\% BSA). The cells were resuspend in staining buffer, and all the cells were stained for CD25. The cells were costained for GITR, CTLA-4, CD44, CD62L, or LAP. The cells were incubated with the antibodies for 30 minutes on ice, washed twice with ice cold staining buffer, and resuspended in staining buffer. The cells were filtered through nylon mesh and analyzed by flow cytometry. The flow cytometry data was evaluated using FlowJo software (Tree Star, Inc, Ashland, OR) gating on the CD25+ $\mathrm{T}$ cells. All flow cytometry results presented are representative of two independent experiments.

2.3. Quantitative Real-Time PCR for FoxP3. Total RNA was isolated from 4- and 24-hour-cultured $\mathrm{T}$ cells with RNeasy mini kit (Qiagen Inc., Valencia, CA) according to the manufacturer's instructions. The cells were washed three times with PBS buffer and collected. They were disrupted, lysed, and homogenized using a QIAshredder spin column (Qiagen Inc.). An equal volume of 70\% ethanol was mixed with the homogenized lysates and applied to RNeasy mini column for adsorption of total RNA to column membrane. RNA was washed once with washing buffer. Further DNA removal was done using a column DNase digestion by RNase-Free DNase Set (Qiagen Inc.). RNA was washed and eluted in RNase-free water. The RNA concentration was determined by spectrophotometry at $260 \mathrm{~nm}$.

The first-strand cDNA synthesis reaction was undertaken with SuperScript First-Strand Synthesis System for RT-PCR kit (Invitrogen, Carlsbad, CA). The isolated total RNA $(5 \mu \mathrm{g})$ was reverse transcribed in a $20 \mu \mathrm{L}$ reaction mixture containing $20 \mathrm{mM}$ Tris- $\mathrm{HCl}$ (pH 8.4), $50 \mathrm{mM} \mathrm{KCl,} 200 \mu \mathrm{M}$ of

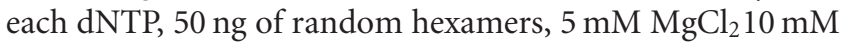
DTT, 40 units of RNaseOUT Recombinant Ribonuclease Inhibitor, and 50 units of SuperScript II RT. The mixture was incubated at $25^{\circ} \mathrm{C}$ for $10 \mathrm{~min}$ and transferred to $42^{\circ} \mathrm{C}$ for $50 \mathrm{~min}$. The RT reaction was terminated by heating the mixture to $70^{\circ} \mathrm{C}$ for $15 \mathrm{~min}$ and then adding 2 units of RNase $\mathrm{H}$ at $37^{\circ} \mathrm{C}$ for $20 \mathrm{~min}$ to remove the RNA from the cDNA:RNA hybrid molecule. 
The $50 \mu \mathrm{L}$ of real-time PCR reaction mixture consisted of a FAM-dye labeled TaqMan MGB predesigned mouse FoxP3 probe of two unlabeled PCR primers, FoxP3F (5' CAGCTGCCTACAGTGCCCCTAG) and FoxP3R (5' CATTTGCCAGCAGTGGGTAG), (Applied Biosystems, Foster City, CA), $25 \mu \mathrm{L}$ of $2 \mathrm{X}$ TaqMan Universal PCR Master Mix containing AmpliTaq Gold DNA Polymerase, AmpErase UNG, dNTPs with dUTP (Applied Biosystems), and $2 \mu \mathrm{L}$ of our sample cDNA (equivalent to $500 \mathrm{ng}$ of RNA). The final reaction concentration of the probes was $250 \mathrm{nM}$ and $900 \mathrm{nM}$ for each primer. Amplification and detection of PCR products were performed using an ABI Prism $7900 H T$ Sequence Detection System with thermal cycling conditions of: $2 \mathrm{~min}$ at $50^{\circ} \mathrm{C}$ for 1 cycle, $10 \mathrm{~min}$ at $95^{\circ} \mathrm{C}$ for 1 cycle, $15 \mathrm{sec}$ at $95^{\circ} \mathrm{C}$, and $1 \mathrm{~min}$ at $60^{\circ} \mathrm{C}$ for 40 cycles. The results were analyzed with SDS 2.1 software (Applied Biosystems). Each assay was carried out in triplicate. The relative expression of FoxP3 mRNA was normalized to the relative expression of GAPDH mRNA (Applied Biosystems). The relative quantization of the FoxP3 mRNA in each sample was measured using the comparative $\mathrm{Ct}$ (threshold cycle) method.

2.4. Sorting, Cytokine Production, and Regulatory T-Cell Assay of $\alpha$-MSH-Treated CD25- $T$ Cells. Purified $\mathrm{CD}^{+}{ }^{+} \mathrm{T}$ cells were stained with anti-CD25-FITC (BD Biosciences) and sorted on the Cytomation MoFlo Cell Sorter (Beckman Coulter, Brea, CA). The CD25- $\mathrm{T}$ cells were collected, and cultured at $4 \times 10^{5}$ cells per well of a 96 well plate. To the cell cultures were added $1 \mu \mathrm{g}$ of anti-Tcr antibody, and $30 \mathrm{pg} / \mathrm{mL}$ of $\alpha$-MSH. After 48 hours, the supernatants were collected and IFN- $\gamma$ and TGF- $\beta$ were measured. The IFN$\gamma$ concentration was measured by ELISA using the R\&D System dual antibody kit. The TGF- $\beta$ concentration was measured using the standard MV1Lu bioassay [18]. To assay for regulatory activity by the $\alpha$-MSH-treated CD $25^{-}$T cells, the $\mathrm{T}$ cells were collected from the cell cultures and $2 \times$ $10^{5} \alpha$-MSH-treated CD25- ${ }^{-}$cells were added to cultures with $2 \times 10^{5}$ anti-Tcr-activated Th1 cells. After 48 hours of incubation, IFN- $\gamma$ production was measured by ELISA.

\section{Results}

3.1. Surface Marker Expression by $\alpha$-MSH-Induced Treg Cells. The $\alpha$-MSH-induced Treg cells are $\mathrm{CD} 25^{+} \mathrm{CD} 4^{+} \mathrm{T}$ cells previously demonstrated to be a stable population of $\mathrm{T}$ cells that suppress the activation of inflammation mediated by effector T cells $[16,17,28-30]$. While it is considered that CD25 is a marker of Treg cells, $\alpha$-MSH-induced Treg cells do not express CD25 any more than effector T cells [17]. Therefore, $\alpha-\mathrm{MSH}$-induced Treg cells were assayed and compared to effector T cells and resting T cells for CTLA4, GITR, CD127, LAP, CD44, and CD62L, which are other Treg and effector T-cell activation markers. The $\alpha$-MSHinduced Treg cells were generated in vitro as done before by treating Tcr-stimulated $\mathrm{CD} 4^{+}$effector T cells with $\alpha$-MSH at a physiological concentration of $30 \mathrm{pg} / \mathrm{mL}$. After 72 hours, the cells were stained and assayed by flow cytometry gating on the $\mathrm{CD} 25^{+} \mathrm{T}$ cells (Figure 1). There was no difference found in the expression of CTLA4, GITR, CD127, CD44, and CD62L between the $\alpha$-MSH induced Treg cells and effector $\mathrm{T}$ cells. The effector T cells and the $\alpha$-MSH-induced Treg cells expressed CTLA4, CD127, CD44, and CD62L but not GITR. The cells had increased expression of CTLA4 and CD62L with depressed expression of CD127 compared to resting T cells. These results show that $\alpha$-MSH-induced Treg cells express markers associated with effector $\mathrm{T}$ cells and not necessarily markers of Treg cells. In addition, the regulatory and effector $\mathrm{CD} 25^{+} \mathrm{CD} 4^{+} \mathrm{T}$ cells expressed both $\mathrm{CD} 44$ and CD62L suggesting that we may have induced $\mathrm{T}$ cells that could also function as memory T cells.

Previously reported findings demonstrated that the suppressive activity of $\alpha$-MSH-induced Treg cells is mediated through TGF- $\beta$ [17]. Flow cytometry analysis for LAP showed significant differences in the surface expression of LAP on the $\alpha$-MSH-induced $\mathrm{CD} 25^{+} \mathrm{CD} 4^{+}$Treg cells to the $\mathrm{CD}_{25}{ }^{+} \mathrm{CD} 4^{+}$effector $\mathrm{T}$ cells. The coexpression of CD25 and LAP shows that the $\alpha$-MSH-induced $\mathrm{CD} 25^{+} \mathrm{CD} 4^{+}$ Treg cells are highly expressive of LAP on their cell surface (Figure 2). There was greater than 10-fold increase in LAP expression on the $\alpha$-MSH-induced Treg cells compared to the stimulated effector $\mathrm{CD} 25^{+} \mathrm{CD} 4^{+} \mathrm{T}$ cells. There is just as striking an increase in LAP expression on $\alpha$-MSH-treated $\mathrm{CD} 25^{-} \mathrm{CD}^{+} \mathrm{T}$ cells, suggesting that $\alpha$-MSH has a general effect of increasing the number of $\mathrm{T}$ cells expressing LAP. This could be due to increased availability of LAP for the $\mathrm{T}$ cells to bind or to general induction of TGF- $\beta$ even in CD25 ${ }^{-} \mathrm{T}$ cells. Therefore, while the $\alpha$-MSH-induced Treg cells express effector and possible memory T-cell markers, they differ from effector $\mathrm{T}$ cells by their surface expression of LAP.

3.2. FoxP3 Expression in $\alpha$-MSH Induced Treg Cells. The $\alpha$ MSH-induced Treg cells were assayed by RT-PCR for expression of FoxP3 message at 4 and 24 hours after treatment (Figure 3). The $\alpha$-MSH treatment induces a substantial early 2 -fold upregulation in FoxP3 message in the activated $\mathrm{T}$ cells that is relatively maintained 24 hours later. This suggests that part of the mechanisms of $\alpha$-MSH induction of regulatory activity involves FoxP3. The untreated effector T cells showed some increase in FoxP3 message that was less than the $\alpha$ MSH-treated cells but greater than unstimulated effector T cells (resting T cells). This suggests that, although $\alpha$-MSH treatment augments FoxP3 expression, there is naturally in the untreated effector T-cell population inducible FoxP3 expressing T cells.

3.3. The Effects of $\alpha-M S H$ on $C D 25^{+}$or $C D 25^{-} T$ Cells. To demonstrate that $\alpha-\mathrm{MSH}$ treatment targets the activity of activated effector $\mathrm{T}$ cells, the effector $\mathrm{T}$ cells $\left(\mathrm{CD} 25^{+} \mathrm{T}\right.$ cells) were removed from the collected draining lymph node $\mathrm{CD} 4^{+}$ T cells before $\alpha$-MSH treatment. The unsorted population of effector T cells produced IFN- $\gamma$ and TGF- $\beta$ and when treated with $\alpha$-MSH produced only TGF- $\beta$ (Figure 4(a)) similar to the cytokine production we have demonstrated before between effector T cells and $\alpha$-MSH-induced Treg 


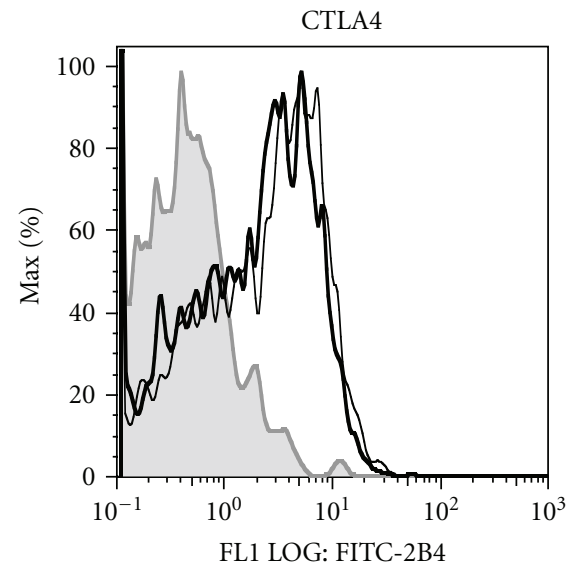

(a)

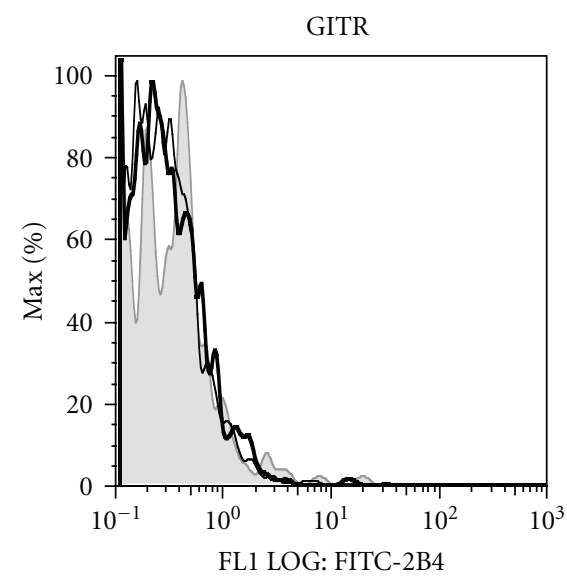

(b)

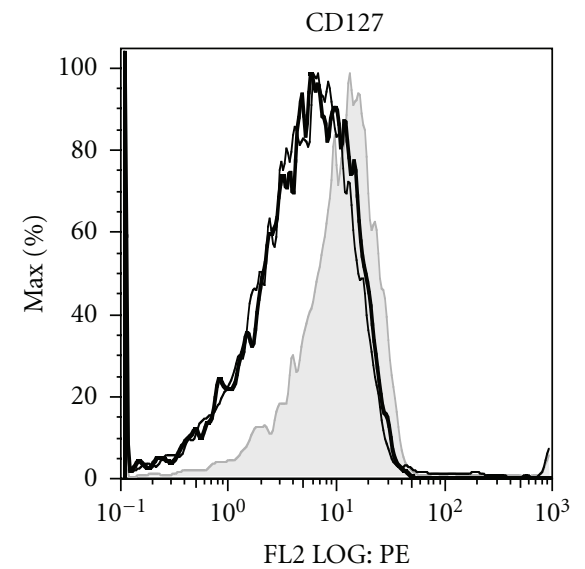

(c)

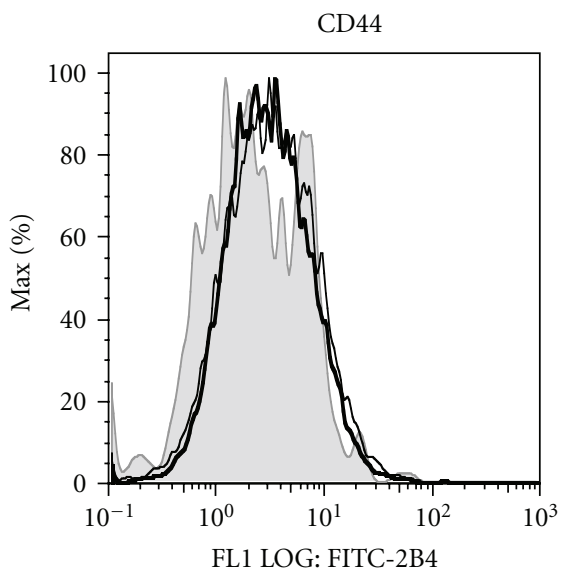

(d)

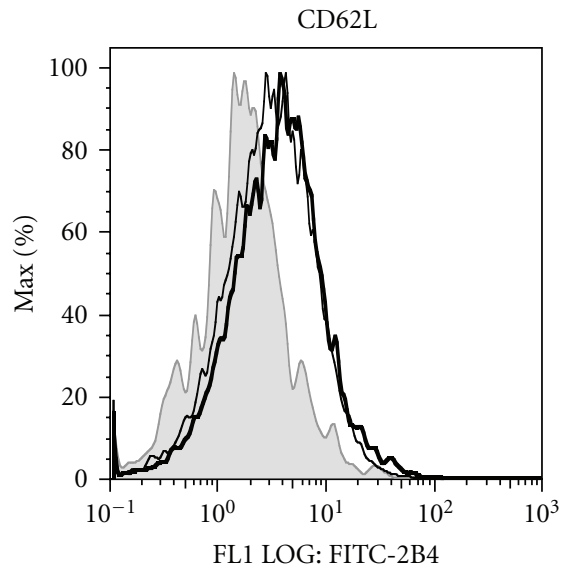

(e)

Figure 1: Flow cytometry analysis of effector/memory T-cell markers on $\alpha$-MSH-induced Treg cells. Isolated draining lymph node CD4 T cells from immunized mice were stimulated and treated with $\alpha-\mathrm{MSH}(30 \mathrm{pg} / \mathrm{mL})$. After 72 hours of incubation, all the cells were stained for CD25. The cells were also stained for CTLA4, GITR, CD127, CD44, or CD62L. The costained cells were analyzed by flow cytometry. Presented results are a representative of two experiments showing the histogram expression of CTLA4, GITR, CD127, CD44, or CD62L on the gated CD25+ T-cell population. The gray shaded histograms are resting T cells; the thin lines are effector T cells; the thick lines are the $\alpha$-MSH-induced Treg cells. There was no significant difference in the expression of CTLA4, GITR, CD127, CD44, or CD62L on the $\alpha$-MSH-induced Treg cells compared to the stimulated effector T cells.

cells $[14,16,17,24,28,30]$. The collected $\mathrm{CD}^{+} \mathrm{T}$ cells depleted of $\mathrm{CD}_{2} 5^{+} \mathrm{T}$ cells were completely devoid of all effector T-cell activity with no IFN- $\gamma$ or TGF- $\beta$ produced (Figure 4(a)). Treating these CD25- $5^{-} D 4^{+} \mathrm{T}$ cells with $\alpha$ MSH-induced TGF- $\beta$ production. This corresponds with the increase of LAP surface expression on $\mathrm{CD} 25^{-} \mathrm{T}$ cells treated with $\alpha-\mathrm{MSH}$ seen in Figure 2. There was no expression of $\mathrm{CD} 25$ on the $\alpha$-MSH-treated and $\alpha$-MSH-untreated sorted $\mathrm{T}$ cells (data not shown). The $\alpha$-MSH-treated CD25- T cells did not suppress IFN- $\gamma$ production by other Th1 cells in culture (Figure 4(b)). Therefore, independent of $\alpha$-MSH induction of regulatory activity, $\alpha$-MSH mediates TGF- $\beta$ production, and the $\alpha$-MSH-induced Treg cells come from $\alpha$-MSH mediating regulatory activity in effector T cells.

\section{Discussion}

The results in this paper propose that $\alpha-\mathrm{MSH}$ induction of regulatory immunity is mediated by $\alpha$-MSH converting effector T cells. The $\alpha$-MSH-induced Treg cells are CD25 $5^{+}$ $\mathrm{CD}^{+}{ }^{+}$expressing CTLA4, CD44, CD62L, and LAP. The effector $\mathrm{CD} 25^{+} \mathrm{CD} 4^{+} \mathrm{T}$ cells expressed the same markers except for LAP. While $\alpha$-MSH-induced TGF- $\beta$ production, it could not induce regulatory activity in naive T cells. This limitation of $\alpha-\mathrm{MSH}$ induction of regulatory activity in effector $\mathrm{T}$ cells and not in naive $\mathrm{T}$ cells has been observed by us many times before but unreported. This implies that the direct effects of $\alpha$-MSH on T cells are limited to antigenexperienced effector $\mathrm{T}$ cells. This explains why it is possible to use $\alpha-\mathrm{MSH}$ to induce antigen-specific Treg cells that target antigen-driven autoimmunity, hypersensitivity, and graft rejection $[16,17,29,30]$. Such an effect of $\alpha$-MSH on effector T cells has implications not only on our own interests in ocular immune privilege but also on the role of $\alpha$-MSH in immune homeostasis.

Since it has been speculated that one of the systemic roles of $\alpha$-MSH is to promote resolution of inflammation [2], the 


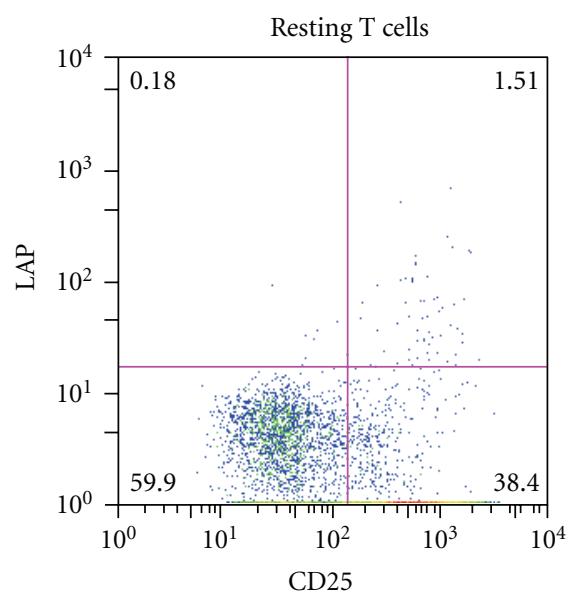

(a)

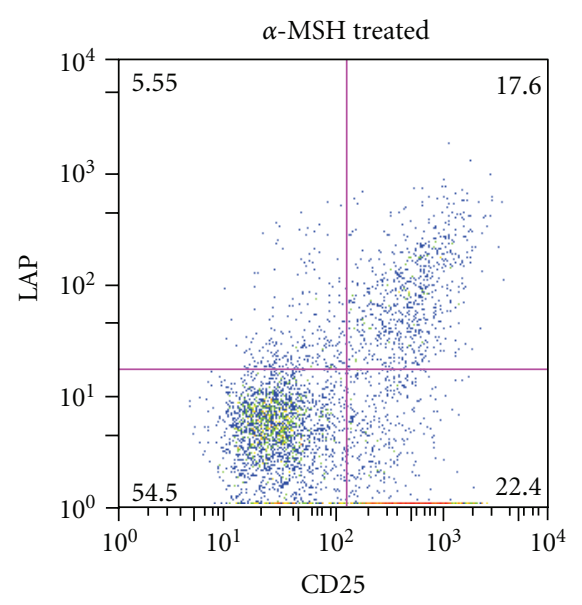

(b)

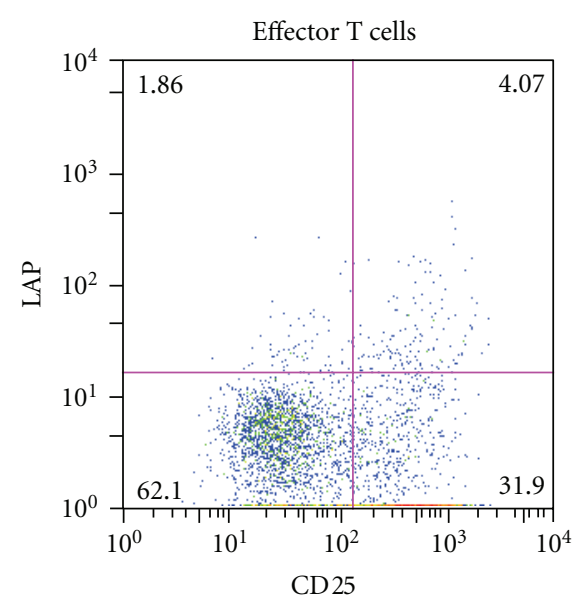

(c)

FIgURE 2: Flow cytometry analysis of LAP expression on $\alpha$-MSH-induced Treg cells. The T cells were collected and treated as in Figure 1, but were costained for CD25 and LAP. The flow cytometry results are presented as dot plots showing T cells expressing CD25 and LAP representing the results of two independent experiments. The expression of LAP on the effector T cells decreases relative to the resting $\mathrm{T}$ cells. In contrast, there is more than a 10 -fold increase in LAP expression on $\alpha$-MSH-induced Treg cells compared to the effector T cells.

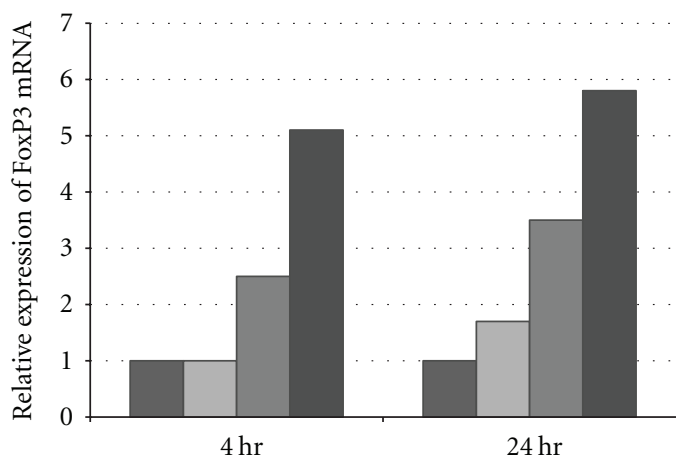

$\alpha-\mathrm{MSH} /$ stimulated

$$
\begin{array}{ll}
\square-/- & \square-/+ \\
\square+/- & +/+
\end{array}
$$

FIgURE 3: Real-time PCR analysis of FoxP3 after $\alpha$-MSH treatment. The $\mathrm{CD}^{+} \mathrm{T}$ cells were isolated from draining lymph nodes, stimulated and treated with $\alpha-\mathrm{MSH}$ as before. At 4 hours and 24 hours after treatment, message was isolated and analyzed by RT-PCR. Presented results are representative of two independent experiments showing the relative levels of FoxP3 message in $\mathrm{CD}^{+}$ $\mathrm{T}$ cells. There is consistently about a 2 fold-higher amount of FoxP3 message in the $\alpha$-MSH-treated $(+/+)$ than in the untreated effector T cells $(-/+)$.

ability of $\alpha$-MSH to induce regulatory activity in activated effector T cells would contribute to resolving inflammation. The suppression of inflammation by $\alpha$-MSH is a balance between its antagonistic activity with proinflammatory cytokines and activators of innate immunity. Therefore, during the resolution phase as proinflammatory signals decline, or are no longer present, the ability for $\alpha$-MSH to induce regulatory activity increases. Because we have found that there is very little difference between effector $\mathrm{T}$ cells and the $\alpha$-MSH-induced Treg cells except for their secreted cytokine profiles and surface expression of LAP, it is to be seen if the maintenance and activation of $\alpha$-MSH-induced Treg cells could also be in balance with proinflammatory signals that drive adaptive immunity.

The constitutive presence of $\alpha$-MSH within the ocular microenvironment contributes to the immunosuppressive mechanisms of ocular immune privilege [14]. The neuropeptide is part of the active ocular mechanisms that suppress effector T-cell activation [32]. Moreover, the presence of $\alpha-\mathrm{MSH}$ is part of the mechanisms used by the ocular microenvironment to turn immunity onto itself, should effector cells be activated within the ocular microenvironment [33]. Recently found are the presence of autoantigenspecific Treg cells within the spleens of mice that have naturally recovered from ocular autoimmune disease [21]. Their presence in the spleen is dependent on the expression of MC5r, the receptor on $\mathrm{T}$ cells through which $\alpha$-MSH induces regulatory activity [20]. In addition, $\alpha$ $\mathrm{MSH}$ treatment of mice with experimental autoimmune encephalomyelitis (EAE) not only prevented further paralysis but also promoted an early recovery of full-motor function [24]. Moreover, in the spleens of these $\alpha$-MSH-treated mice were Treg cells that suppress EAE. Therefore, augmenting $\alpha$ $\mathrm{MSH}$ has the potential to promote activation of regulatory activity in effector $\mathrm{T}$ cells during an inflammatory response. Also, it appears that once the $\mathrm{T}$ cells are set in this direction, it may be difficult for $\alpha$-MSH-induced Treg cells to revert back into effector $\mathrm{T}$ cells.

Very little is understood about the intracellular signals triggered by $\alpha$-MSH within T cells. The melanocortin receptors are G-coupled protein receptors that elevate cAMP when bound with $\alpha$-MSH [34]; however, this alone cannot account for all the actions induced by $\alpha$-MSH in T cells. The induction of regulatory activity by $\alpha$-MSH in T cells is through MC5r [17]. When $\alpha$-MSH binds MC5r it has been found to activate within immune cells the JAK2/STAT1 and ERK1/2 pathways $[35,36]$. Therefore, $\alpha$-MSH through MC5r 

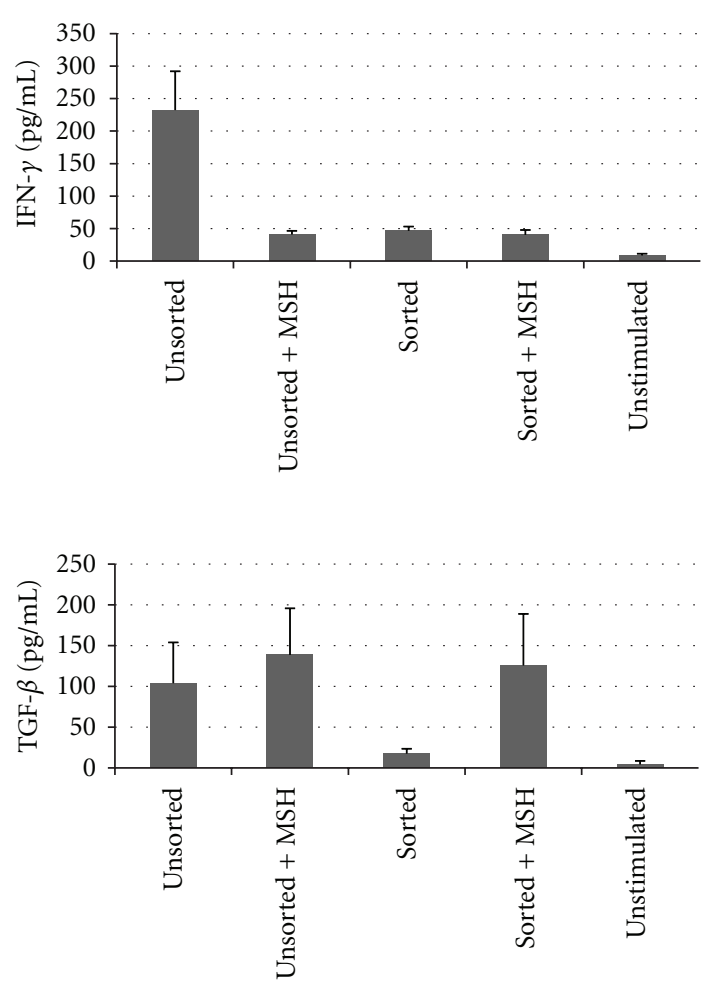

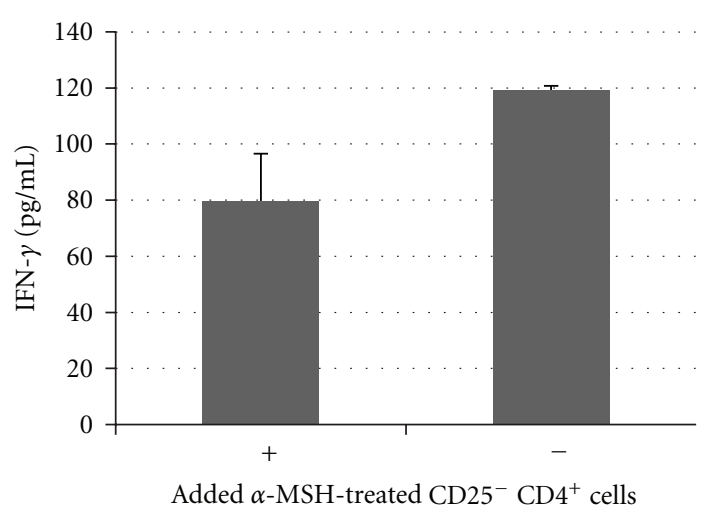

(b)

(a)

Figure 4: The effects of $\alpha-\mathrm{MSH}$ on $\mathrm{CD} 25^{-} \mathrm{CD} 4^{+} \mathrm{T}$ cells. The CD4 T cells were isolated from the draining lymph node as in Figure 1 and were stained with CD25 antibody. The stained cells were sorted, and the CD25- cells were placed in culture, stimulated, and treated with $\alpha$-MSH. (a) After 48 hours, the supernatant was assayed for IFN- $\gamma$ and TGF- $\beta$. The sorted CD25- CD4 ${ }^{+}$T cells (Sorted) did not produce IFN- $\gamma$ or TGF- $\beta$; however, when treated with $\alpha$-MSH (Sorted + MSH) did produce TGF- $\beta$ but not IFN- $\gamma$. (b) The $\alpha$-MSH-treated CD25$\mathrm{CD} 4^{+} \mathrm{T}$ cells were transferred to cultures of activated Th1 cells. After 48 hours of incubation IFN- $\gamma$ was measured in the supernatant. There was no statistical difference in IFN- $\gamma$ production by the Th1 cells in culture with or without $\alpha$-MSH-treated CD $25^{-}$CD $4^{+}$T cells.

is at least potentially linked to signals that mediate cellular differentiation and cytokine production. What is not known is how this is linked to $\alpha$-MSH-mediated induction of Treg cells.

The $\alpha$-MSH-induced Treg cells are T cells that retain several features of effector $\mathrm{T}$ cells and have also features and functions associated with natural and inducible Treg cells. Previous publications have shown that the $\alpha$-MSHinduced Treg cells are limited in cytokine production to TGF- $\beta$, proliferate, must be activated through their Tcr to mediate regulatory activity, and their induction is dependent on the expression of MC5r [17]. To these findings the $\alpha$ MSH-induced Treg cells express surface LAP, corresponding to their use of TGF- $\beta$ to suppress effector T cells through contact or enhanced release of active TGF- $\beta$ [17]. Also, the $\alpha$ MSH-induced Treg cells are from the effector $\mathrm{CD} 25^{+} \mathrm{CD} 4^{+}$ T-cell population indicating $\alpha$-MSH-mediated conversion of effector T cells into Treg cells.

\section{Acknowledgments}

This research was supported in part by a grant from the NIH through the NEI, Grant EY010752, and by the Massachusetts
Lions Eye Research Foundation. The authors thank the Schepens Eye Research Institute's core animal and flow cytometry facilities, and Mr. David Yee and Dr. Dayu Li for their technical support.

\section{References}

[1] A. Guijarro, A. Laviano, and M. M. Meguid, "hypothalamic integration of immune function and metabolism," Progress in Brain Research, vol. 153, pp. 367-405, 2006.

[2] J. M. Lipton and A. Catania, "Anti-inflammatory actions of the neuroimmunomodulator $\alpha$-MSH," Immunology Today, vol. 18, no. 3, pp. 140-145, 1997.

[3] Y. C. L. Tung, S. J. Piper, D. Yeung, S. O'Rahilly, and A. P. Coll, "A comparative study of the central effects of specific proopiomelancortin (POMC)-derived melanocortin peptides on food intake and body weight in Pomc null mice," Endocrinology, vol. 147, no. 12, pp. 5940-5947, 2006.

[4] T. Brzoska, D. H. Kalden, T. Scholzen, and T. A. Luger, "Molecular basis of the $\alpha$-MSH/IL-1 antagonism," Annals of the New York Academy of Sciences, vol. 885, pp. 230-238, 1999.

[5] J. G. Cannon, J. B. Tatro, S. Reichlin, and C. A. Dinarello, " $\alpha$ Melanocyte stimulating hormone inhibits immunostimulatory and inflammatory actions of interleukin 1," Journal of Immunology, vol. 137, no. 7, pp. 2232-2236, 1986. 
[6] T. Ichiyama, T. Sakai, A. Catania, G. S. Barsh, S. Furukawa, and J. M. Lipton, "Inhibition of peripheral NF- $\kappa$ B activation by central action of $\alpha$ - melanocyte-stimulating hormone," Journal of Neuroimmunology, vol. 99, no. 2, pp. 211-217, 1999.

[7] D. Li and A. W. Taylor, "Diminishment of $\alpha$-MSH antiinflammatory activity in MC1r siRNA-transfected RAW264.7 macrophages," Journal of Leukocyte Biology, vol. 84, no. 1, pp. 191-198, 2008.

[8] T. A. Luger, "Neuromediators-a crucial component of the skin immune system," Journal of Dermatological Science, vol. 30, no. 2, pp. 87-93, 2002.

[9] I. Mandrika, R. Muceniece, and J. E. S. Wikberg, "Effects of melanocortin peptides on lipopolysaccharide/interferongamma-induced NF-kappaB DNA binding and nitric oxide production in macrophage-like RAW 264.7 cells: evidence for dual mechanisms of action," Biochemical Pharmacology, vol. 61, no. 5, pp. 613-621, 2001.

[10] A. Sarkar, Y. Sreenivasan, and S. K. Manna, “ $\alpha$-Melanocytestimulating hormone induces cell death in mast cells: involvement of NF- $\kappa$ B," FEBS Letters, vol. 549, no. 1-3, pp. 87-93, 2003.

[11] A. W. Taylor, "The immunomodulating neuropeptide alphamelanocyte-stimulating hormone ( $\alpha$-MSH) suppresses LPSstimulated TLR4 with IRAK-M in macrophages," Journal of Neuroimmunology, vol. 162, no. 1-2, pp. 43-50, 2005.

[12] R. A. Star, N. Rajora, J. Huang, R. C. Stock, A. Catania, and J. M. Lipton, "Evidence of autocrine modulation of macrophage nitric oxide synthase by $\alpha$-melanocyte-stimulating hormone," Proceedings of the National Academy of Sciences of the United States of America, vol. 92, no. 17, pp. 8016-8020, 1995.

[13] L. W. Martin and J. M. Lipton, "Acute phase response to endotoxin: rise in plasma $\alpha$-MSH and effects of $\alpha$-MSH injection," American Journal of Physiology, vol. 259, no. 4, pp. R768-R772, 1990.

[14] A. W. Taylor, J. W. Streilein, and S. W. Cousins, "Identification of alpha-melanocyte stimulating hormone as a potential immunosuppressive factor in aqueous humor," Current Eye Research, vol. 11, no. 12, pp. 1199-1206, 1992.

[15] C. H. Lau and A. W. Taylor, "The immune privileged retina mediates an alternative activation of J774A.1 cells," Ocular Immunology and Inflammation, vol. 17, no. 6, pp. 380-389, 2009.

[16] K. Namba, N. Kitaichi, T. Nishida, and A. W. Taylor, "Induction of regulatory $\mathrm{T}$ cells by the immunomodulating cytokines $\alpha$-melanocyte-stimulating hormone and transforming growth factor- $\beta 2$," Journal of Leukocyte Biology, vol. 72, no. 5, pp. 946952, 2002.

[17] A. W. Taylor and K. Namba, "In vitro induction of $\mathrm{CD} 25^{+} \mathrm{CD}^{+}$regulatory $\mathrm{T}$ cells by the neuropeptide alphamelanocyte stimulating hormone ( $\alpha$-MSH)," Immunology and Cell Biology, vol. 79, no. 4, pp. 358-367, 2001.

[18] A. W. Taylor, P. Alard, D. G. Yee, and J. W. Streilein, "Aqueous humor induces transforming growth factor- $\beta$ (TGF$\beta$ )-producing regulatory T-cells," Current Eye Research, vol. 16, no. 9, pp. 900-908, 1997.

[19] A. W. Taylor, J. W. Streilein, and S. W. Cousins, "Alphamelanocyte-stimulating hormone suppresses antigenstimulated T cell production of gamma-interferon," Neuroimmunomodulation, vol. 1, no. 3, pp. 188-194, 1994.

[20] A. W. Taylor, N. Kitaichi, and D. Biros, "Melanocortin 5 receptor and ocular immunity," Cellular and Molecular Biology, vol. 52, no. 2, pp. 53-59, 2006.

[21] N. Kitaichi, K. Namba, and A. W. Taylor, "Inducible immune regulation following autoimmune disease in the immune-privileged eye," Journal of Leukocyte Biology, vol. 77, no. 4, pp. 496-502, 2005.

[22] D. J. Lee, D. J. Biros, and A. W. Taylor, "Injection of an alpha-melanocyte stimulating hormone expression plasmid is effective in suppressing experimental autoimmune uveitis," International Immunopharmacology, vol. 9, no. 9, pp. 10791086, 2009.

[23] P. Hamrah, Z. Haskova, A. W. Taylor, Q. Zhang, B. R. Ksander, and M. R. Dana, "Local treatment with alpha-melanocyte stimulating hormone reduces corneal allorejection," Transplantation, vol. 88, no. 2, pp. 180-187, 2009.

[24] A. W. Taylor and N. Kitaichi, "The diminishment of experimental autoimmune encephalomyelitis (EAE) by neuropeptide alpha-melanocyte stimulating hormone $(\alpha-\mathrm{MSH})$ therapy," Brain, Behavior, and Immunity, vol. 22, no. 5, pp. 639646, 2008.

[25] T. Nishida, S. Miyata, Y. Itoh et al., "Anti-inflammatory effects of alpha-melanocyte-stimulating hormone against rat endotoxin-induced uveitis and the time course of inflammatory agents in aqueous humor," International Immunopharmacology, vol. 4, no. 8, pp. 1059-1066, 2004.

[26] K. Shiratori, K. Ohgami, I. B. Ilieva, Y. Koyama, K. Yoshida, and S. Ohno, "Inhibition of endotoxin-induced uveitis and potentiation of cyclooxygenase- 2 protein expression by $\alpha$ melanocyte-stimulating hormone," Investigative Ophthalmology and Visual Science, vol. 45, no. 1, pp. 159-164, 2004.

[27] S. Gatti, G. Colombo, R. Buffa et al., " $\alpha$-melanocytestimulating hormone protects the allograft in experimental heart transplantation," Transplantation, vol. 74, no. 12, pp. 1678-1684, 2002.

[28] A. W. Taylor, D. G. Yee, T. Nishida, and K. Namba, "Neuropeptide regulation of immunity: the immunosuppressive activity of alpha-melanocyte-stimulating hormone ( $\alpha$-MSH)," Annals of the New York Academy of Sciences, vol. 917, pp. 239-247, 2000.

[29] T. Nishida and A. W. Taylor, "Specific aqueous humor factors induce activation of regulatory T cells," Investigative Ophthalmology and Visual Science, vol. 40, no. 10, pp. 22682274, 1999.

[30] T. F. Ng, N. Kitaichi, and A. W. Taylor, "In vitro-generated autoimmune regulatory $\mathrm{T}$ cells enhance intravitreous allogeneic retinal graft survival," Investigative Ophthalmology and Visual Science, vol. 48, no. 11, pp. 5112-5117, 2007.

[31] D. J. Biros, K. Namba, and A. W. Taylor, "Alpha-MSH regulates protein ubiquitination in T cells," Cellular and Molecular Biology, vol. 52, no. 2, pp. 33-38, 2006.

[32] A. W. Taylor, "Ocular immunosuppressive microenvironment," Chemical Immunology and Allergy, vol. 92, pp. 71-85, 2007.

[33] A. W. Taylor, “Ocular immune privilege," Eye, vol. 23, no. 10, pp. 1885-1889, 2009.

[34] J. Voisey, L. Caroll, and A. van Daal, "Melanocortins and their receptors and antagonists," Current Drug Targets, vol. 4, no. 7, pp. 586-597, 2003.

[35] J. J. Buggy, "Binding of $\alpha$-melanocyte-stimulating hormone to its G-protein-coupled receptor on B-lymphocytes activates the Jak/STAT pathway," Biochemical Journal, vol. 331, no. 1, pp. 211-216, 1998.

[36] A. R. Rodrigues, D. Pignatelli, H. Almeida, and A. M. Gouveia, "Melanocortin 5 receptor activates ERK1/2 through a PI3K-regulated signaling mechanism," Molecular and Cellular Endocrinology, vol. 303, no. 1-2, pp. 74-81, 2009. 


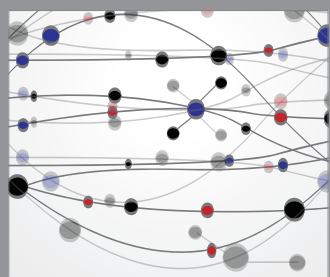

The Scientific World Journal
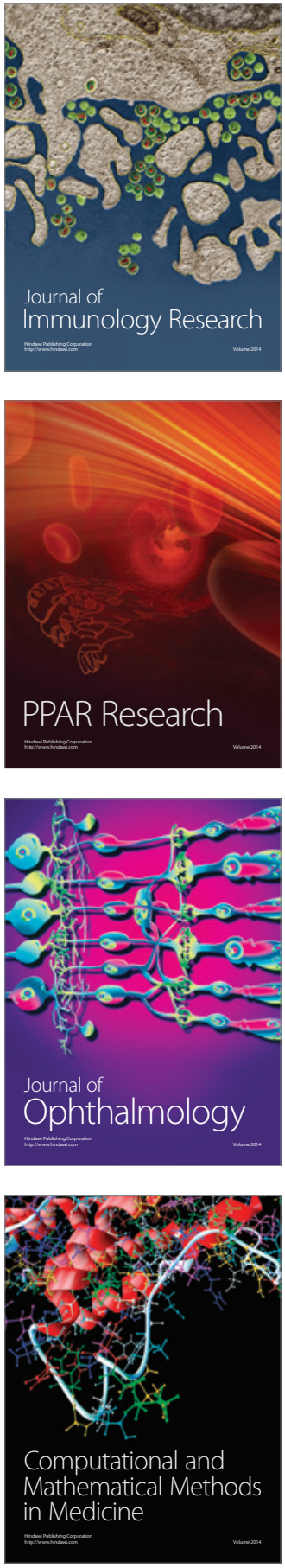

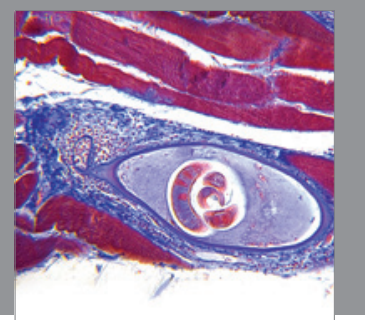

Gastroenterology

Research and Practice
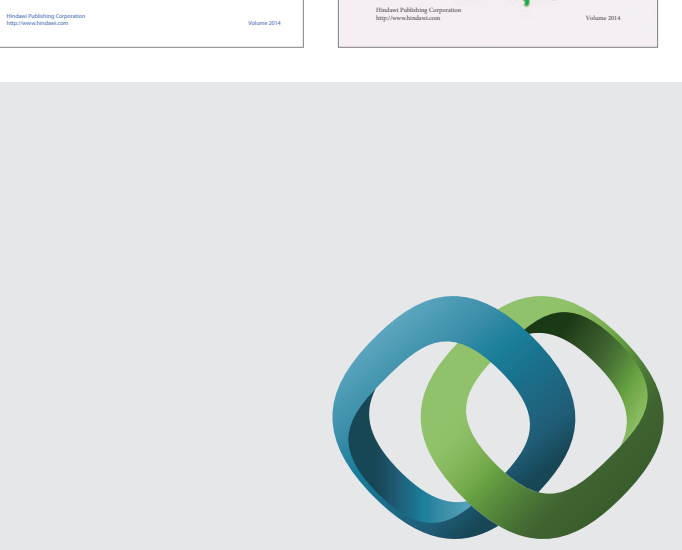

\section{Hindawi}

Submit your manuscripts at

http://www.hindawi.com
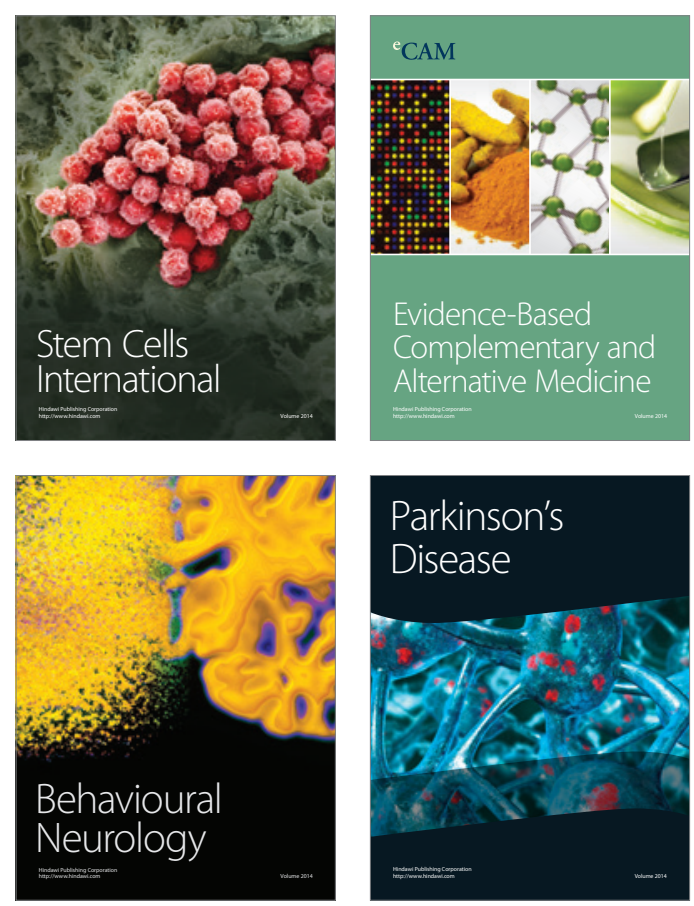

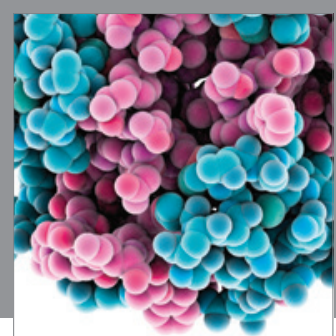

Journal of
Diabetes Research

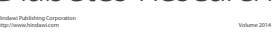

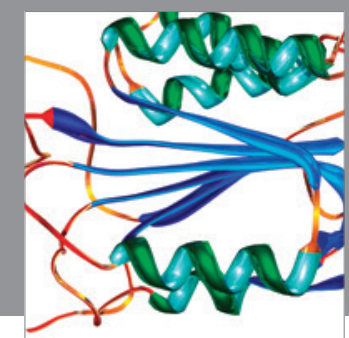

Disease Markers
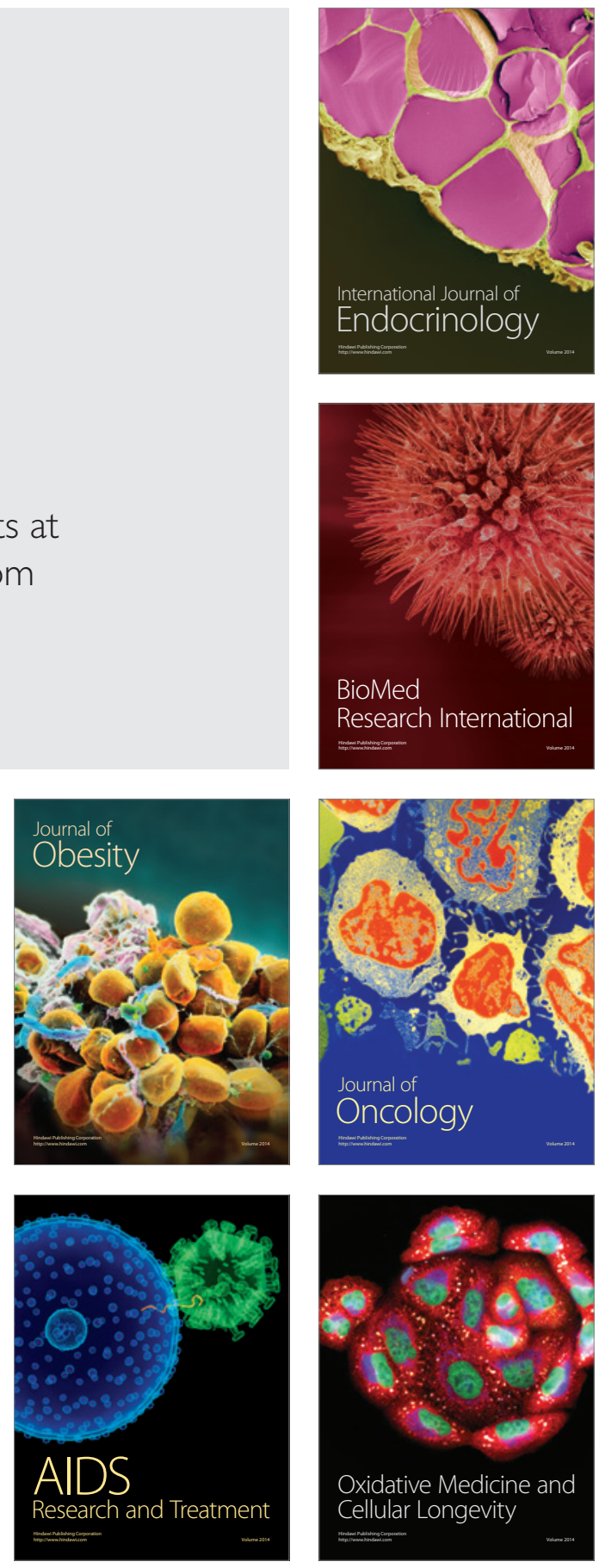